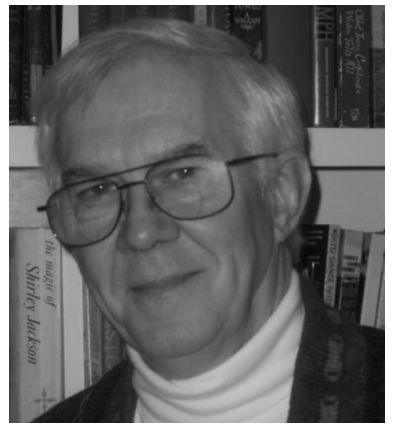

\section{Designing Optical Systems, Part I: Analysis}

Bob Shannon, the former director of the Optical Sciences Center at the University of Arizona, has said that he valued the thin lens formula because of the consulting that came his way when someone designed an optical system using that simple equation. I also heard of a university professor who was designing a 10-in. diameter achromat. After a number of telephone calls to the software vendor, the calls stopped. At first they thought that he had given the problem to a more qualified person...or perhaps fobbed it off on a grad student. Two months later he was back screaming at technical support. He had designed, ordered, and received the lens and put it on the test bed and got "garbage." The support person asked what had he done? He said that he designed a perfect system. So tech support asked him to run an on-axis spot diagram. When he hesitated, he was then walked through the commands to display one. When the spot diagram appeared on his monitor, there was more screaming.

"That's what my image looks like!"

"Well, what merit function did you use?"

"Huh?"

"How did you determine your lens was optimized?"

"Well, when the back focal points for my two end wavelengths were equal. Why?"

How do you keep bad designs from being generated by good optical design programs? In this day and age, efficient high-speed desktop computers can rapidly generate optimized optical systems at the push of a button...and another push of a button... and another push of a button.... Perhaps these programs should have a little routine that counts button pushes and then displays a notice: "You have just pushed the optimize button $\mathrm{X}$ times. We suggest that you take a look at your design."

The problem stems from powerful software used by technical persons (and their managers) who have little or no background in a specialty. This is not unusual in modern life. Much of our ability to master the software that we use is acquired without any training. Therefore, why should optical design be any different? The reason it is different is that the output of an optical design program can be used to produce costly, unusable pieces of beautifully shaped glass. It can also tie up valuable fabrication facilities that others need for their projects.

The trouble with the use of these programs is that, even in the case of very conscientious designers, the solution to the new problem looks very much like the previous one they tackled. This occurs because there is no understanding of basic optics and the limitations that physics and fabrication play in finding a successful solution to an optical design problem. And while the optical software houses provide training in the use of their programs at introductory, intermediate, and advanced levels, they cannot easily teach an overall philosophy of design and explore alternatives, except as they highlight a feature of their program. That task is, or should be, the responsibility of an optics educator. So if we could just get all those university optics professors to do their jobs, we wouldn't have a problem!

One of the realities of today's university faculty structure is that it is based on the profit motive. It's not called "profit," of course. The correct term is "overhead." And in search of such profits, universities offer incredible amounts of start-up funding to attract new professors to work there. It is understood that these profs, with this newly acquired tailwind, will sail forth with dazzling plans for exploration, promising to bring back the undiscovered treasures of their field. And what are the undiscovered treasures of optical design? Where are the breakthroughs to be made in ray tracing? Big-budget projects that would support a research-grade optical educator are few and far between. But important optical systems that require good optical designers with good preparation abound. Designers with strengths in illumination optics and scattering analysis are needed also. So what's a profession to do? 